\title{
COREOGRAFIAS DIDÁTICAS E CENÁRIOS INOVADORES NA EDUCAÇÃO SUPERIOR
}

\author{
DIDACTIC CHOREOGRAPHIES AND INNOVATIVE SCENARIOS \\ IN HIGHER EDUCATION
}

\section{COREOGRAFÍAS DIDÁCTICAS Y ESCENARIOS INNOVADORES EN LA EDUCACIÓN SUPERIOR}

\author{
Maria Auxiliadora Soares Padilha ${ }^{1}$ \\ Miguel Angel Zabalza Beraza ${ }^{2}$ \\ César Vinícius de Souza ${ }^{3}$
}

Resumo: O objetivo deste artigo é discutir sobre coreografias didáticas e cenários inovadores na educação superior. Para isso, apresentamos dois estudos realizados no contexto de uma universidade pública federal. Um deles com a aplicação de atividades gamificadas e outro com a integração de tecnologias como recursos didáticos em atividades de ensino e aprendizagem, seja na sala de aula ou em outros espaços, presencialmente ou virtualmente. Os referenciais principais que fundamentam os estudos são as discussões sobre inovação pedagógica de Cunha (2008), Zabalza (2006) e Silva (2011). A metodologia principal dos dois estudos foi a análise dessas coreografias didáticas. Os cenários propostos e a colocação em cena ultrapassaram as quatro paredes da sala de aula. A ruptura com o paradigma tradicional pôde ser constatada em várias das atividades realizadas e também no processo de idealização e planejamento delas. O protagonismo dos alunos foi a categoria de inovação mais destacada nas duas experiências e o professor como coreógrafo estratégico, provocando oportunidades para esse protagonismo e para aprendizagens profundas e significativas.

Palavras-chave: Coreografias didáticas; Inovação pedagógica; Educação superior; Cenários inovadores.

\footnotetext{
Submetido em: 21/09/2017 - Aceito em: 04/011/2017 - Publicado em: 13/11/2017.

1 Pedagoga, Mestre e Doutora em Educação. Professora do Programa de Pós-Graduação em Educação Matemática e Tecnológica da UFPE. Pós-Doutorado em Coreografias Didáticas Inovadoras com Integração de TIC na Universidade de Santiago de Compostela.

${ }^{2}$ Pedagogo e Doutor em Psicologia. Presidente da Asociación Iberoamericana de Didáctica Universitaria.

${ }^{3}$ Pedagogo, Mestre em Educação Matemática e Tecnológica pela UFPE. Professor de Ensino Superior.
} 
Abstract: The purpose of this article is to discuss didactic choreographies and innovative scenarios in higher education. For this we present two studies carried out in the context of a federal public university. One of them with the application of gamified activities and another with the integration of technologies such as didactic resources in teaching and learning activities, whether in the classroom or in other spaces, presentially or virtually. The main references that base the studies are the discussions on pedagogical innovation of Cunha (2008), Zabalza (2006) and Silva (2011). The main methodology of the two studies was the analysis of these didactic choreographies. The proposed scenarios and the staging went beyond the four walls of the classroom. The rupture with the traditional paradigm could be seen in several of the activities carried out and also in the process of idealization and planning of the same. The protagonism of the students was the most outstanding innovation category in both experiences and the teacher as a strategic choreographer, provoking opportunities for this protagonism and for deep and meaningful learning.

Keyword: Didactic choreography; Pedagogical innovation; College education; Innovative scenarios.

RESUMEN El propósito de este artículo es para discutir didactic choreographies y crear escenarios en la educación superior. En el caso de la federal public university. Uno de ellos con la aplicación de las actividades de juego y otra con la integración de las tecnologías, como los recursos didácticos en las actividades de aprendizaje y de aprendizaje, en el aula o en otros lugares, presencial o simplemente. En el caso de las mujeres, la mayoría de las veces, la mayoría de las mujeres, La principal cuestión de los dos estudios fue el análisis de estos didácticos choreographies. Los panoramas y los ascensores se extienden más allá de las cuatro paredes de la sala. La ruptura con el paradigma tradicional se puede ver en varias de las actividades realizadas fuera y también en el proceso de idealización y planificación del mismo. El protagonismo de los estudiantes fue la muestra más importante de la categoría de innovación en ambas experiencias y el profesorado a la aspirante choreographer, proboking opportunities for this protagonism and for deep and meaningful learning.10, justificado, espaçamento simples.

PALABRAS CLAVE: Coreografías didácticas; Innovación pedagógica; Educación universitaria; Escenarios innovadores. 


\section{INTRODUÇÃO ÀS COREOGRAFIAS DIDÁTICAS}

O objetivo deste artigo é discutir sobre coreografias didáticas e cenários inovadores na educação superior. Para isso, apresentamos dois estudos realizados no contexto de uma universidade pública federal. Um deles com a aplicação de atividades gamificadas e outro com a integração de tecnologias como recursos didáticos em atividades de ensino e aprendizagem, seja na sala de aula ou em outros espaços, presencialmente ou virtualmente. Nesse sentido, alunos e professores inauguram cenários diferenciados que não se limitam mais às quatro paredes da sala de aula. Aliás, o espaço de ensinar e aprender não tem mais fronteiras e limites. Ele é composto por cenários diversos, justamente pelas possibilidades que as metodologias e tecnologias proporcionam às situações vividas por professores e alunos. Essas experiências foram realizadas à luz das coreografias didáticas. A analogia nos permite compreender melhor como esses cenários se compõem e se integram na busca de atingir aprendizagens profundas e significativas.

Para iniciar a discussão sobre as coreografias é necessário clarear o sentido do termo no âmbito da Didática, pois se trata de um conceito ainda pouco utilizado e que pode provocar uma discussão superficial ou equivocada se adotado de maneira literal. É necessário, portanto, voltar o foco da atenção didática ao ambiente de aprendizagem às condições contextuais em que os estudantes constroem suas aprendizagens. A metáfora da coreografia não está longe de alguns conceitos que vêm enriquecendo ultimamente a leitura didática, como a ideia da "aprendizagem situada" de Lave e Wenger (1990) e Mc Lelland (1995), na medida em que a aprendizagem se vincula à atividade, ao contexto e à cultura na qual ela se produz.

O que Oser e Baeriswyl (2001) apresentaram é uma conexão entre os elementos do contexto (coreografias externas) e os processos internos que mobilizam os estudantes no próprio processo de aprendizagem. Partindo do mundo da dança, procuraram estabelecer a seguinte analogia: a performance de um bailarino nunca é independente da coreografia em que se produz a atuação dele. A organização do espaço, do ritmo, dos acessórios, dos elementos que configuram o entorno, etc. condicionam de modo relevante a qualidade da

\begin{tabular}{l|l|l} 
v.1 & n.1
\end{tabular}

p. 117




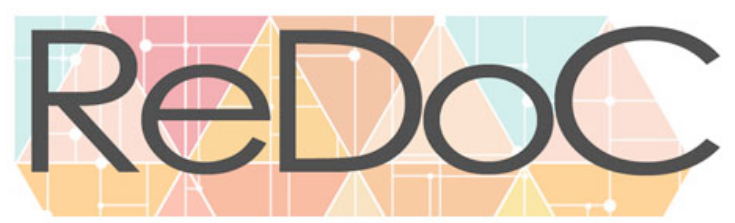

Revista Docência e Cibercultura

atuação. Como eles mesmos explicam:

(...) os passos da dança respondem simultaneamente a dois tipos de demandas: por um lado, o bailarino pode criar livremente no espaço disponível e mostrar todo o seu repertório expressivo; por outro, o artista se vê limitado pelos elementos que constituem a cenografia, o ritmo, a estrutura métrica, a forma e sequência da música etc. (p. 1043).

O que existe de interessante nessa metáfora é que a ideia da coreografia remete a um conjunto de elementos e condições que se articulam intencionalmente. Essa é a tarefa dos coreógrafos: pessoas especializadas em criar ambientes capazes de propiciar boas atuações dos bailarinos, capazes de conseguir o melhor deles. Não seria essa uma boa analogia para o que deve ser o ensino? Afinal, podemos considerar que ensinar é o arranjo intencional de situações apropriadas para que a aprendizagem possa ocorrer.

Nesse sentido, os professores montam coreografias e "encenações" que canalizam o processo de aprendizagem dos estudantes. Essas situações podem ser presenciais e ocorrer em espaços concretos (as salas de aula, os laboratórios, os locais de estágio) ou podem ser virtuais (em sistemas de ensino a distância ou online). Porém, em todo caso, possuem o mesmo papel: definem, concretizam e operacionalizam oportunidades de aprendizagem.

A diferença entre um professor experiente e um menos experiente não reside apenas (e provavelmente, não tanto) no que cada um deles sabe sobre a própria matéria ou no quão competente cada um deles é na investigação e pesquisa, mas sim, na perícia que possui para organizar as situações didáticas de tal modo que seus estudantes alcancem um nível de aprendizagem profundo e significativo.

Partindo desses pressupostos, Oser e Baeriswyl (2001) apresentam três componentes básicos nesta perspectiva dos processos de ensino e aprendizagem:

a) uma coreografia externa e superficial, composta pelos elementos materiais, organizativos, operativos e dinâmicos que configuram um espaço de ação e pensamento;

b) uma coreografia interna e profunda que consiste nas operações mentais e nas dinâmicas afetivas ou emocionais que ocorrem dentro dos sujeitos. Eles definem esse processo interno como uma sequência de operações que levam a uma realização ou atuação e que podem ser observadas pelos professores devido a externalizações feitas pelos estudantes, como pontos grifados de um texto, 


\section{Revista Docência e Cibercultura}

evidência de certos pontos na fala, respostas orais ou escritas, produção de materiais etc;

c) O produto ou resultado da aprendizagem. O aluno domina o novo conhecimento proposto e/ou está em condições de realizar as atuações, habilidades práticas ou respostas atitudinais aprendidas.

Definitivamente, mesmo sem ser uma proposta demasiadamente inovadora (retorna a ideia já bem conhecida de contexto, processo, produto), possui o atrativo de aproximar-se da aprendizagem a partir da visão do mundo da arte e oferecer um espectro quase infinito de possibilidades de configuração de cenários e ambientes estimulantes e potenciadores de aprendizagens ricas. O mais inovador que podemos pensar, nesse caso, é tornar a aprendizagem condicionante do ensino e não o contrário, como geralmente estamos acostumados. Ou seja, o professor precisa antecipar as aprendizagens necessárias para seu aluno, e somente então, definir as estratégias mais adequadas para fomentar as operações cognitivas, motoras e afetivas necessárias para tais aprendizagens.

Assim, neste artigo, apresentamos duas experiências na educação superior, em que os cenários são propostos de forma a promover coreografias didáticas que potencializam aprendizagens profundas e significativas.

\section{INOVAÇÃO PEDAGÓGICA NA EDUCAÇÃO SUPERIOR}

Inovar não é fácil. Em praticamente nenhum setor profissional. Nem todo mundo se sente confortável com mudanças, guinadas bruscas no ambiente de trabalho ou experiências completamente diferentes do que já está acostumado a enfrentar no seu dia a dia. Ainda mais nas universidades que, apesar de ter um compromisso com a pesquisa, o desenvolvimento, a produção e a difusão do conhecimento, parecem ser avessas a mudanças, presas que estão ao sistema tradicional de gestão acadêmica e de ensino.

Alguém já disse que tudo em educação é mais demorado, que as mudanças devem ser pensadas, refletidas, testadas, analisadas até a exaustão, para que aí sim, possam ser postas em prática. Contudo, vivemos hoje em um mundo bastante diferente, que exige velocidade e, por vezes, as ideias, recursos e conceitos ficam obsoletos muito rapidamente.

n.1




\section{Revista Docência e Cibercultura}

Nesse sentido, apoiamo-nos na afirmação de Mota e Scott (2014, p. 51) quando declaram que a inovação é "normalmente de natureza experimental, portanto, está mais provavelmente sujeita a testes e taxas razoáveis de falhas". E, além disso, "é consequência do encorajamento a mudanças via exploração legítima das fronteiras epistêmicas, éticas, disciplinares e de práticas estabelecidas"(p. 51).

Entretanto, não se inova com espontaneísmo ou improvisações. É preciso ousar e enfrentar o novo, com coragem, responsabilidade e competência. Inovar requer envolvimento de todos que estão envolvidos no processo. E, para isso, é necessário comprometimento pessoal e institucional. Sem a participação da instituição, apoiando e fomentando ações e sujeitos inovadores, temos apenas um 'arranjo inovador' (PADILHA; ZABALZA, 2015), em que professores e alunos lutam contra o imobilismo da gestão acadêmica com seus próprios recursos. Assim, concordamos com Zabalza e Zabalza (2013) quando afirmam que toda inovação depende de fatores pessoais e também institucionais.

Inovação é mudança, porém, não somente isso. É contextual, ou seja, uma determinada mudança pode ser inovação em um contexto e não ser em outro. O objetivo principal da inovação na educação deve ser ampliar o interesse, a participação e o sucesso dos alunos em suas aprendizagens.

Segundo Cebrián (2003, p. 23), a inovação educativa é

(...) toda ação planejada para produzir uma mudança nas instituições de ensino que proporcione uma melhora nos pensamentos, na organização e no planejamento da política educacional, assim como nas práticas pedagógicas, e que permitam um desenvolvimento profissional e institucional com o compromisso e compreensão de toda a comunidade escolar.

É preciso, pois, investir numa cultura institucional de inovação, que proporcione e fomente as condições necessárias para que a comunidade acadêmica, como um todo, possa mudar e inovar. A inovação não pode estar somente nas ações das pessoas, individualmente, precisa compor e produzir o currículo. Só assim, a inovação pode ser institucionalizada. Fora isso, são ações desconexas que impactam muito pouco na formação dos sujeitos.

Por outro lado, Zabalza (2004, p. 117) afirma que "um dos principais inimigos da inovação autêntica são as inovações forçadas (pela via formal, burocrática ou administrativa)". Portanto, a inovação deve ser pensada, planejada, promovida e avaliada 


\section{Revista Docência e Cibercultura}

pelo conjunto de pessoas que usufruem de seus benefícios, juntamente com a gestão da instituição.

Silva (2011) fez um estudo sobre aulas inovadoras e, segundo ela, em nenhuma das aulas analisadas houve uma ruptura epistemológica, porque ainda estamos em uma fase de transição paradigmática e não existe, na maioria das instituições, um projeto políticopedagógico construído coletivamente, "que favoreça a constituição de práticas inovadoras institucionalizadas"(p. 196). Para a autora, as aulas inovadoras são orientadas pelos seguintes princípios: contextualização, dialogicidade, diversidade, ética, integralidade, transitoriedade. E, além disso, algumas relações estão presentes nas aulas inovadoras: professor-aluno; objetivos-avaliação; conteúdo-método; conhecimento local-total; ensinopesquisa; teoria-prática; movimento-afetividade; tempo-espaço.

Cunha $(2009$, p. 16) aponta condições e características necessárias para a inovação na educação: "ruptura com a forma tradicional de ensinar e aprender", "gestão participativa", "reconfiguração de saberes", "reorganização da relação teoria/prática" e "perspectiva orgânica no processo de concepção, desenvolvimento e avaliação da experiência desenvolvida".

Mudança de paradigma é, portanto, o principal mote da inovação pedagógica e, esse novo paradigma está relacionado ao papel do aluno no processo de ensino e aprendizagem, em sua consciência e responsabilidade pelo seu aprender.

Neste estudo, portanto, o foco são coreografias didáticas que buscam romper com um paradigma tradicional e põe no aluno a luz do processo educativo, pensando no docente como aquele que vai oportunizar estratégias onde esses alunos possam criar e construir suas aprendizagens de forma profunda e significativa. As experiências apresentadas serão analisadas do ponto de vista das coreografias didáticas, considerando que são situações isoladas e, portanto, 'arranjos inovadores' levados a cabo por professores e alunos que ousam mudar, ensinando e aprendendo juntos. 


\section{Revista Docência e Cibercultura}

\section{CENÁRIOS E COREOGRAFIAS NA EDUCAÇÃO SUPERIOR}

O cenário é o espaço, presencial ou virtual, onde a coreografia acontece. No palco, o cenário pode ser classificado no que tange à disposição do público e sua relação com a cena apresentada. Para escrever a coreografia, o coreógrafo precisa pensar os passos da dança, mas também o cenário e como a dança irá ocorrer nesse espaço, físico ou virtual. Ele é composto por cores, texturas, móveis e artefatos de um modo geral que são dispostos de maneira estratégica para dar sentido à cena e também aos personagens.

Da mesma forma, na coreografia didática o professor precisa pensar sobre os passos que seus alunos irão desenvolver, mas também no cenário da aprendizagem, de maneira estratégica. O cenário de aprendizagem, atualmente, está mais variado e os alunos influenciam muito mais na escolha dos componentes desse espaço do que em outros tempos. Diversos fatores influenciam na organização de um cenário ou ambiente de aprendizagem, seja ele presencial ou virtual. Partindo da compreensão de como o aluno irá aprender, o professor planeja como seus alunos irão se mover nesse cenário. Também procura prever as relações que se estabelecem entre alunos-alunos, alunos-professor e as atividades definidas e desenvolvidas a partir dessas relações. Nesse cenário, o professor observa o processo, orienta, facilita, investiga, regula, ou seja, programa um ambiente propício para a produção das operações cognitivas, motoras, afetivas e atitudinais necessárias e, consequentemente, a construção de aprendizagens.

Segundo Zabalza (2009), numa coreografia o professor deve "organizar um processo complexo de oportunidades diferenciadas de aprendizagem profunda e acompanhar o itinerário pessoal que cada um dos estudantes segue nesse processo" (p. 76). Nesse sentido, os cenários vão compor esse processo complexo, auxiliando os passos e as estratégias propostas pelo coreógrafo e dançarinos.

Com o desenvolvimento das TIC e a introdução delas no ambiente educacional, os cenários educativos estão se modificando. De um cenário mínimo, com a presença apenas de professor, alunos, cadernos, lápis, lousa e giz, passamos a conviver, cada vez mais, com cenários mais complexos e recheados de tecnologias das mais variadas. Contudo, apenas a

\begin{tabular}{l|l|l} 
v.1 & n.1
\end{tabular}

p. 122

Set/Dez.2017

ISSN 2594-9004 


\section{Revista Docência e Cibercultura}

introdução desses recursos no ambiente educativo não significa uma aprendizagem mais profunda e duradoura.

Segundo Cabero et al. (2007), os cenários de aprendizagem, atualmente, possuem as seguintes características: são baseados em recursos, são multimídias e apresentam uma estrutura não linear. Ainda segundo os autores, atualmente, o uso das TIC favorece a criação de cenários flexíveis, considerando essa flexibilidade como: flexibilidade temporal e espacial para interação e recepção de informação, flexibilidade para interação em diferentes códigos, flexibilidade para escolha de itinerários formativos, e flexibilidade para escolha do tipo de comunicação. Assim, nos dias de hoje, com a diversidade de materiais à disposição dos professores, tanto em relação à quantidade como à qualidade, é possível criar um verdadeiro ecossistema virtual para a aprendizagem, ou seja, novas e potentes cenografias de comunicação síncronas e assíncronas em diferentes suportes (CABERO, 2015).

\section{PRIMEIRO CENÁRIO: GAMIFICAÇÃO E COREOGRAFIAS NA EDUCAÇÃO SUPERIOR}

Esta experiência ocorreu em uma turma do curso de Pedagogia de uma universidade pública brasileira no contexto das atividades programadas para a disciplina, tomando um tema específico para o seu desenvolvimento.

A prática da gamificação ainda é pouco conhecida e trabalhada no âmbito deste curso, e até os alunos - jovens universitários - demonstraram desconhecimento e mesmo surpresa com a proposta feita. Este texto relaciona esta experiência de gamificação com os pressupostos da coreografia didática (ZABALZA, 2006), apontando para a pertinência desta prática no sentido do estabelecimento de práticas pedagógicas inovadoras no ensino superior.

O termo gamificação surgiu pela primeira vez em 2002, citado por Nick Pelling, para descrever as atividades de sua empresa de consultoria que visava modificar normas e regras do funcionamento de empresas. A partir disso, o termo foi pouco utilizado e citado, ganhando força somente a partir de 2010 por meio de outros estudos na área.

Para Kapp (2012), gamificação é a utilização de mecânicas, estética e game-think,

\begin{tabular}{l|l} 
v.1 & n.1
\end{tabular}




\section{Revista Docência e Cibercultura}

baseadas nos jogos, para engajar, motivar ações, promover aprendizado e resolver problemas. Podemos pensar então em maneiras de transpor elementos dos games, tão adorados pelos jovens, para ambientes não-games, como escolas, empresas, indústrias etc.

Ao nos questionarmos em por que fazer isso, podemos pensar em como é difícil manter a concentração dos estudantes por quatro horas em sala de aula e como é tão fácil que esse mesmo estudante gaste horas a fio em um game sem pausas e totalmente imerso naquela realidade. Em seu livro "Realidade em Jogo" (2012), Jane McGonigal nos chama atenção para o quão divertido um jogo pode ser e quão desafiador e gratificante é jogar. A autora descreve as atividades exercidas em World of Warcraft como um "ciclo vicioso de produtividade" em que o jogador precisa realizar tarefas repetitivas para treinar e aprimorar seu personagem para assim ter acesso a atividades mais desafiadoras e resolver os problemas daquele mundo.

Como então pensar maneiras de tornar esse estudante tão produtivo em sua aprendizagem da mesma forma que ele é quando está jogando? A proposta da gamificação indica que o professor deve planejar a coreografia de sua aula tal como um game designer concebe um jogo, utilizando os elementos dos games para criar um ambiente de aprendizagem mais motivador, instigante e que faça sentido para o estudante.

O professor, como um dos atores responsáveis pela construção ou transformação do saber do aluno, deve estar preparado para trabalhar com diversas situações que sejam significativas para a aprendizagem do aluno. Para Zabalza (2006), o processo de aprendizagem do aluno está intimamente ligado à maneira, dinâmica e didática com que o professor relaciona os conteúdos. Sendo assim, o processo de aprendizagem está totalmente ligado ao processo de ensino.

A partir disso, podemos compreender a forma como o professor pensa e antecipa as aprendizagens e os cenários onde seus alunos irão aprender e, além disso, como ele pode, a partir dessa antecipação, promover situações em que os alunos sejam mais participativos em suas próprias aprendizagens.

A utilização da gamificação deve vir acompanhada de estratégias efetivas criadas pelo professor, de maneira que vise contemplar uma aprendizagem colaborativa, baseada em problemas reais, e fazendo com que os estudantes assumam a responsabilidade com a 


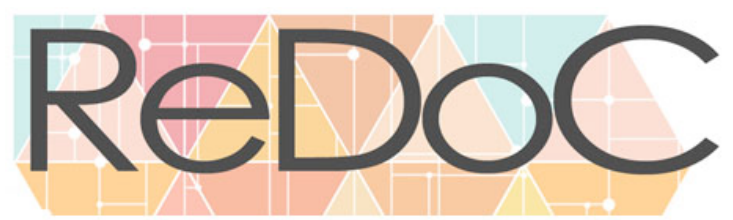

\section{Revista Docência e Cibercultura}

própria aprendizagem também.

Para entendermos os processos criativos do professor sobre sua forma de ensinar, utilizamos o conceito de Oser e Baeriswyl (2001) de Coreografias Didáticas, analogia essa que relaciona o processo educativo aos atos de um musical, que são coreografados e pensados antecipadamente e se dividem em quatro momentos: a) Antecipação; b) Processo I - colocação em cena; c) Processo II - modelo base de aprendizagem e; d) Produto do aprendizado. Sendo assim, este trabalho toma como referencial o conceito de Coreografias Didáticas proposto por Oser e Baereswyl (2001) por se tratar de uma coreografia na qual docente e estudantes trabalham juntos, em busca de um mesmo objetivo: a aprendizagem profunda e significativa.

\section{METODOLOGIA DO PRIMEIRO CENÁRIO}

A disciplina, campo deste estudo, foi "História da Educação no Brasil" no curso de Pedagogia da Universidade Federal de Pernambuco, Brasil. O objetivo principal foi gamificar algumas atividades e criar novas, de forma que o cenário da sala de aula se organizasse em outros cenários. Para servir de suporte, a construção dessa atividade teve como base as coreografias didáticas, nas quais o professor antecipa as aprendizagens previstas de seus alunos, a colocação em cena das atividades planejadas, a forma de avaliação dessas atividades e os produtos criados pelos estudantes por meio de suas pesquisas, entrevistas e outras atividades.

Sendo assim, o professor planejou as aulas em formato de missões que consistiu em um tutorial, disponibilizado em formato de texto de apoio do conteúdo para os estudantes e uma pequena exposição do contexto brasileiro antes dos acontecimentos que seriam estudados a seguir. Depois, foram distribuídas as missões aos estudantes, durante a semana, por meio de whatsapp ou email, de forma que o tempo pedagógico foi ampliado para além do tempo de $2 \mathrm{~h}$ da aula presencial.

Para compreender o que foi trabalhado na aula gamificada, utilizaremos os elementos de gamificação de Kapp (2012) aplicados:

Objetivo - Algumas semanas antes da aula gamificada, o professor já começou a revelar sobre a atividade e qual o seu principal objetivo: compreender o significado 


\section{Revista Docência e Cibercultura}

do "Manifesto dos Pioneiros da Educação Nova" e seus impactos na sociedade brasileira.

Regras - Ao longo da semana que ocorreu a gamificação, foram explicadas as missões e as regras para se fazer a(s) atividade(s). Sempre que uma missão era passada para a turma, uma explicação sobre ela e a forma de fazer eram fornecidas para elucidar o processo.

Conflito - As missões apresentadas continham não só a indicação de algo a ser feito como também a construção da relação do aspecto histórico trabalhado com a atualidade educacional.

Competição - Embora o professor da disciplina não quisesse trabalhar a gamificação como um processo competitivo, durante as atividades e realização delas surgiu um clima de competição entre os grupos e a busca por uma "vitória".

Cooperação - Algumas das missões demandaram muito tempo e esforço, sendo assim, os grupos precisaram gerenciar seus recursos para criar uma estratégia de otimização das atividades. Exemplo: uma das atividades foi a realização de entrevistas com algumas pessoas e criação de um produto com esse conteúdo para ser apresentado à turma. Os grupos se dividiram e, enquanto alguns alunos entrevistaram as pessoas, outros gravaram, outros criaram o modelo de apresentação como vídeo e outros procuraram links entre o que foi dito pelos entrevistados e o texto.

Tempo - Como a atividade final aconteceu apenas em uma aula, foi utilizado o grupo de whatsapp da turma, provocando assim uma ampliação do tempo pedagógico. Além disso, determinadas atividades tinham prazo, gerando certa urgência na realização delas.

Recompensa - Foram criadas duas maneiras de recompensar os alunos por seus feitos. A primeira, relacionada aos troféus que, a pedido do professor, não poderiam ser quantitativos, ou seja, quem tinha mais troféus ganharia a atividade. Ao invés disso, foram criados troféus com tags específicas, como: troféu por ter concluído a missão 1, por ter concluído a missão 2, "Primeiro de todos" (relacionado a quem terminava a missão primeiro), "Mais diversidade" (relacionado a quem 


\section{Revista Docência e Cibercultura}

tinha entrevistado mais tipos de sujeitos, como professor, aluno, funcionários etc.). Além do professor ter promovido a entrega desses tipos de troféus, foram entregues troféus para que os próprios grupos premiassem uns aos outros por seus feitos, gerando assim um momento de avaliação entre eles e descontração. A segunda forma de recompensa foi por meio de livros. Todos os grupos ganharam a mesma quantidade de livros por terem participado da atividade gamificada, fazendo com que não houvesse um sentimento de ganhar ou perder, mas sim de participação.

Feedback - Os troféus, além de recompensa, serviram também como feedback, para que os participantes soubessem os seus feitos e como foram realizados. Além disso, durante a fala dos alunos, o professor estava sempre fazendo anotações sobre o que era dito e, ao final de cada missão, ele retomava, sintetizava e complementava as falas e as atividades dos participantes. Isso sempre fazia com que os participantes se preparassem melhor para a próxima etapa das missões.

Níveis - O professor organizou as atividades a partir de um texto-base sobre o conteúdo e uma discussão prévia, e assim ambos os recursos passaram a funcionar como tutorial. As missões atuaram como níveis, a medida em que iam aumentando o grau de complexidade e a inter-relação, ou seja, o que foi construído/debatido na missão 1 foi retomado na missão 3 para aprofundamento ou discussão de outras questões.

História - Por se tratar da disciplina "História da Educação no Brasil", os contextos, fatos e enredos ganharam destaque, seja pela contextualização e recriação nas missões de pesquisas sobre a época do "Manifesto dos Pioneiros da Educação Nova" ou pelos impactos que nossa sociedade teve com isso.

Estética - A sala de aula foi modificada com um quadro de troféus, o que gerou exaltação e empolgação da turma. Além disso, o cenário de aprendizagem foi ampliado devido ao uso de internet, ida a campo para entrevistas etc. 


\section{Revista Docência e Cibercultura}

\section{RESULTADOS DO PRIMEIRO CENÁRIO}

Entre os resultados alcançados com a experiência de gamificação, podemos destacar uma maior mobilização dos estudantes para a realização das tarefas propostas. As estratégias utilizadas, acompanhando os passos da coreografia didática, permitiram que os estudantes fossem descobrindo a cada passo o que era preciso fazer, bem como se preparar para a atividade seguinte.

Essa mobilização permitiu um maior envolvimento dos estudantes em relação a outras atividades realizadas na disciplina, aspecto que foi percebido principalmente nos momentos de apresentação das missões.

Outro resultado observado foi o uso de criatividade e colaboração pelos estudantes na realização das atividades, envolvendo diferentes técnicas tanto para a obtenção de dados necessários ao cumprimento das missões como para a apresentação dos produtos.

Mesmo tendo sido uma experiência pontual, realizada em um curto período de uma disciplina de graduação, é possível dizer que a gamificação como estratégia didática pode ser diretamente relacionada com as coreografias didáticas, uma vez que as etapas/momentos das coreografias foram vividas de forma planejada, organizada, tendo os estudantes como protagonistas do próprio processo de aprendizagem.

Para além da simples constatação dos resultados obtidos, foi percebido também que a proposta, bem organizada e devidamente apresentada aos estudantes, foi capaz de criar um contexto propício ao desenvolvimento das aprendizagens, o que foi destacado por alguns estudantes ao final do processo. Isso comprova a importância de professores e alunos terem clareza do processo de ensino e aprendizagem e dos feedbacks constantes.

Nesse sentido, a gamificação se alia a outros modelos didáticos para a superação de paradigmas tradicionais de ensino já consolidados no ensino superior. É preciso, pois, criar oportunidades de ampliar o espectro de ação dos alunos, na busca por uma aprendizagem autônoma, colaborativa e criativa. Para isso, os professores devem rever o processo deles de criação de cenários e coreografias que possibilitem aos alunos serem protagonistas da própria aprendizagem. 


\section{SEGUNDO CENÁRIO: TECNOLOGIAS E COREOGRAFIAS DIDÁTICAS}

Este estudo ocorreu numa disciplina de mestrado e doutorado intitulada "Integração de TIC na docência universitária", em um programa de pós-graduação de uma universidade pública federal. Este é um estudo descritivo e objetiva analisar o cenário proposto com a introdução das TIC na coreografia de uma disciplina do ensino superior. Os sujeitos do estudo foram uma professora e seus alunos. A disciplina foi acompanhada durante todo o período e os dados utilizados para análise foram coletados do grupo do Facebook da turma e por observação participante. A análise utilizada foi a Análise Textual Discursiva. Segundo Moraes e Galiazzi (2011) essa técnica de análise permite criar um novo texto através de um processo auto-organizado de construção de compreensão do emergente que existe no texto dito.

\section{RESULTADOS DO SEGUNDO CENÁRIO}

A disciplina contou com 12 alunos e foi promovida numa carga horária de 30 h. Foram 15 encontros, sendo o primeiro utilizado para introdução da temática geral (TIC no ensino superior), início do planejamento com os alunos e o último para avaliação da disciplina e das aprendizagens. Portanto, foram utilizados 13 encontros para discussão de temáticas específicas, relacionadas ao tema.

Para definição da coreografia a ser desenvolvida, inicialmente, a professora discutiu com os alunos sobre inovação pedagógica no ensino superior. Em um estudo sobre experiências inovadoras, Cunha (2008) propõe 7 condições e características que correspondem a práticas inovadoras: (1) ruptura paradigmática com a forma tradicional de ensinar e aprender; (2) gestão participativa dos sujeitos no processo de aprendizagem, desde sua concepção até a análise de resultados; (3) reconfiguração de saberes, relacionada ao abandono das estratificações dualistas entre saber científico/saber popular, teoria/prática, corpo/alma, razão, emoção, objetividade/subjetividade; (4) reorganização da relação teoria/prática; (5) perspectiva orgânica do processo de concepção, desenvolvimento e avaliação da experiência desenvolvida, com a busca da coerência constante entre objetivos, desenvolvimento e avaliação; (6) inclusão das relações sócioafetivas como 


\section{Revista Docência e Cibercultura}

condição da aprendizagem significativa; (7) protagonismo dos alunos como responsáveis pela própria aprendizagem.

O desafio apresentado à turma foi desenvolver a disciplina observando os critérios de inovação pedagógica, proposto por Cunha (2008), na introdução das TIC em sala de aula. A proposição foi feita, considerando que grande parte dos gestores e professores universitários acredita que a simples introdução de qualquer tecnologia em sala de aula seja uma inovação pedagógica. Contudo, o que conduz à inovação é a mudança de atitude do professor para mobilizar as operações de pensamento necessárias para produzir a aprendizagem prevista. Promover um processo de ensino e aprendizagem que rompa com uma didática memorística, mecânica e pouco significativa requer muito mais que a presença de tecnologias de ponta na sala de aula.

Assim, a coreografia didática proposta teve como objetivo promover um cenário educativo inovador, baseado no compartilhamento e na produção colaborativa de aprendizagens. O plano da disciplina foi apresentado com apenas metade das atividades previstas. Tanto essas atividades já previstas como as demais, a serem ainda planejadas, deveriam ser discutidas e definidas pelos alunos e com eles, numa tentativa de romper com a prática tradicional em que o professor define todo o programa e, também, para o exercício da gestão compartilhada, possibilitando maior protagonismo e autonomia dos discentes.

As temáticas a serem definidas pelos alunos deveriam estar diretamente relacionadas à ementa da disciplina e poderiam ser discutidas com toda a turma. Dos 13 encontros, a professora ficou responsável por organizar 8 e os alunos por 5. Esse número não foi definido previamente, mas discutido a cada encontro com a turma. Algumas vezes, os temas foram trocados, porque a turma sugeria outro que mais interessava ou complementava um anterior.

A metodologia foi diversificada, mas sempre contava com a participação dos alunos, tanto na aula, propriamente dita, como em um grupo criado no Facebook, por sugestão dos próprios estudantes. Estes se dividiram em grupos para planejar, organizar e ministrar as 5 aulas previstas, com apoio da professora. Em vários momentos da disciplina, os alunos foram convidados a refletir sobre suas próprias aprendizagens e a forma como estava sendo produzido o processo, numa tentativa de promover uma ação metacognitiva. A professora 


\section{Revista Docência e Cibercultura}

os incitava a tomar as rédeas de suas aprendizagens e, tanto ela como os alunos admitiram o quanto era difícil essa gestão compartilhada, pois ao mesmo tempo que a docente sentia falta do controle completo do processo, os discentes sentiam-se incomodados por terem que sair de uma postura passiva e confortável e se tornarem corresponsáveis por seus processos de aprendizagem. Contudo, para eles, esse era um desafio que deveria ser enfrentado.

O cenário tecnológico foi composto por notebook e smartphones, dos próprios alunos e professora, e diversos aplicativos e softwares. O mais utilizado foi o grupo no Facebook, pois ele possibilitou que tanto a professora quanto os alunos disponibilizassem arquivos, vídeos e atividades, além de permitir a construção coletiva de documentos. O plano da disciplina foi o documento que todos puderam construir colaborativamente, sugerindo, comentando e incluindo temas e atividades a serem trabalhadas durante a disciplina. Outros recursos utilizados foram o blog e o Evernote, um aplicativo que permite a produção colaborativa de cadernos, com a possibilidade de inserir textos, vídeos, áudios etc.

A cada aula, os alunos promoviam a utilização de recursos que eles tinham interesse, aliados ao conteúdo da disciplina. Dessa forma, temas como gamificação, metodologias ágeis, tendências tecnológicas, entre outros, estimulavam o debate sobre o ensino superior na atualidade, a profissionalização docente, a pedagogia universitária e a integração das TIC no processo de ensino e aprendizagem, que era o mote principal da disciplina. $O$ desenvolvimento das atividades em sala de aula era sempre precedido de um movimento intenso de atividades na internet. Vídeos, textos e hiperlinks eram disponibilizados no grupo do Facebook e o debate sempre foi bastante participativo.

A condição tecnológica proporcionada pela universidade foi muito ruim. Apesar de ter um laboratório de informática com 20 computadores, apenas 8 estavam funcionando e, mesmo assim, sem nenhum acesso à internet, nem mesmo para os equipamentos dos alunos. A sala muito suja, com um ar-condicionado que fazia bastante barulho. Assim, observamos que a coreografia institucional não foi muito propícia à coreografia da professora e alunos, ocorrendo o que chamamos de 'arranjo inovador' (PADILHA, ZABALZA, 2015), quando professores e alunos conseguem inovar em sala de aula, mesmo sem quase nenhum apoio institucional, apenas com o interesse e suporte de seus próprios recursos. 


\section{Revista Docência e Cibercultura}

$\mathrm{Na}$ avaliação da disciplina, os alunos consideraram que conseguiram inovar. Disseram que quebraram várias barreiras da abordagem tradicional, passaram a se preocupar mais com a reflexão sobre suas próprias aprendizagens e admitiram que a tecnologia possibilitou maior participação de todos nas atividades e, consequentemente, na gestão delas. Outro ponto bastante evidenciado nas falas dos alunos é que cada um construiu o próprio percurso e, portanto, o uso das TIC, nas atividades a distância, permitiu que cada um seguisse seu estilo e seu ritmo, ocorrendo o que Cabero et al. (2007) defendem como a flexibilidade proporcionada pelas tecnologias. Diante disso, podemos pensar que as coreografias construídas individualmente, a partir dos diversos artefatos dos cenários disponibilizados, contribuíram para uma maior consciência de suas próprias aprendizagens.

Durante a disciplina, observamos que o que mais se destacou durante o processo de ensino e aprendizagem, muito mais que as próprias tecnologias, foi o cenário que elas possibilitam, que é um cenário de mais autonomia para o aluno e de autogestão. Os recursos didático-tecnológicos utilizados, aliados a uma perspectiva de inovação pedagógica (CUNHA, 2008), possibilitaram a participação ativa e criativa dos alunos, que organizaram coreografias didáticas a partir de seus interesses no conteúdo e também de suas experiências tecnológicas. Os alunos tiveram a oportunidade de escolher os conteúdos e recursos que mais thes interessavam e puderam compor o cenário de aprendizagem em colaboração entre eles e a professora. Dessa forma, concluímos que o cenário de aprendizagem com TIC, muito mais do que motivador, é um estimulante para aprendizagens mais conscientes, autônomas e colaborativas.

\section{CONSIDERAÇÕES}

Segundo Zabalza (2009), uma das principais competências que o professor universitário deve possuir é a capacidade de planejar o processo de ensino e aprendizagem na perspectiva do aluno. Ou seja, cada vez mais precisamos pensar nas estratégias de aprendizagem e não de ensino. Pensar assim é promover coreografias didáticas construtivas e 'ricas', com reais potencialidades de impacto sobre a aprendizagem. Para isso, há que se produzir um cenário diverso e que extrapole as quatro paredes da sala de aula.

A aprendizagem e o ensino não estão mais restritos ao ambiente da sala de aula e 


\section{Revista Docência e Cibercultura}

tampouco ao espaço presencial e fixo. O espaço da aprendizagem é fluido e diverso. Professores e alunos compartilham aprendizagens em diversos espaços virtuais e presenciais. Além disso, tanto a mudança na perspectiva do ensino para a aprendizagem como o maior envolvimento dos alunos promovem novas perspectivas para a docência universitária.

Os cenários propostos e a colocação em cena ultrapassaram as quatro paredes da sala de aula. A ruptura com o paradigma tradicional pôde ser constatada em várias das atividades realizadas e também no processo de idealização e planejamento delas. Cada vez mais precisamos pensar nas estratégias de aprendizagem e não de ensino. Pensar assim é promover coreografias didáticas construtivas e 'ricas', com reais potencialidades de impacto sobre a aprendizagem. Para isso, há que se produzir um cenário diverso e que extrapole as quatro paredes da sala de aula.

O protagonismo dos alunos foi a categoria de inovação mais destacada nas duas experiências e o professor como coreógrafo estratégico, provocando oportunidades para esse protagonismo e para aprendizagens profundas e significativas.

Nas duas experiências, percebemos que os cenários propostos geraram mais motivação nos alunos. Essa motivação, relacionada ao interesse, ao conteúdo, aos desafios e aos feedbacks promovidos, gera o engajamento do aluno e, consequentemente, uma aprendizagem mais profunda e duradoura. Observou-se que quando os alunos são estimulados a agir e criar suas próprias estratégias de aprendizagem, eles se mobilizam e se engajam, dando mais significado a elas.

O objetivo principal das coreografias didáticas apresentadas foi, justamente, proporcionar aos estudantes o protagonismo necessário para esse engajamento. Acreditase, e esses estudos confirmam, que os alunos precisam estar envolvidos e conscientes de seu processo de aprendizagem, e é papel do docente proporcionar as oportunidades dessa construção, antecipando as aprendizagens necessárias, envolvendo os alunos no processo de planejamento, organização, colocação em cena e avaliação. Este é um pressuposto que queremos agregar às coreografias didáticas. Não existe coreografia sem escrita conjunta, de professores e alunos, coreógrafos e dançarinos, dos passos que serão e estão sendo 'dançados'. 


\section{Revista Docência e Cibercultura}

\section{REFERÊNCIAS}

CABERO, J. Innovando en educación: la atualización de nuevos escenarios tecnologicos.Organización y Gestión Educativa. N. 2. 2015. (p. 14-18).

CABERO, J.; CEJUDO, M. del C. L.; ROMÁN-GRAVÁN, P. La tecnología cambió los escenarios: el efecto Pigmalión se hizo realidad. Comunicar: Revista científica iberoamericana de comunicación y educación, N. 28, 2007. (p. 177-182).

CEBRIÁN, M. (Coord.) Enseñanza virtual para la innovación universitaria. Narcea Ediciones: Madrid, 2003.

CUNHA, M. I. da. Inovações pedagógicas na universidade. M. CUNHA, S. SOARES; M. L. RIBEIRO, Docência universitária: profissionalização e práticas educativas. Feira de Santanta, BA: Editora UEFS, 2009.

CUNHA, M. I. Inovações pedagógicas: o desafio da reconfiguração de saberes na docência universitária. Universidade de São Paulo: Pró-Reitoria de Graduação, 2008.

KAPP, K.M. The gamification of learning and instruction: Game-based methods and strategies for training and education. San Francisco: Pfeiffer, 2012.

LAVE, J.; WENGER, E. Situated Learning: Legitimate Periperal Participation. Cambridge, UK: Cambridge University Press, 1990.

McGONIGAL, J. A realidade em jogo. Rio de Janeiro: BestSeller, 2012.

McLELLAN, H. (1995). Situated Learning Perspectives. Englewood Cliffs, NJ, 1995.

MORAES, R.; GALIAZZI, M do C. (2011). Análise textual discursiva. Ijuí: Editora Unijuí, 2011.

MOTA, R.; SCOTT, D. Educando para inovação e aprendizagem independente. Rio de Janeiro: Elsevier, 2014.

OSER, F. K.; BAERISWYL, F. J. Choreographies of Teaching: Bridging Instruction to Learning. In RICHARDSON, V. (Edit): Handbook of Research on Teaching (4a ed) (1031-1065). Washington: AERA, 2001.

PADILHA, M.A.S.; ZABALZA, M.A. Coreografias didáticas no ensino superior: um cenário de integração de TIC na docência universitária. Relatório de pós-doc. Universidade de Santiago de Compostela, 2015.

SILVA, E. F. Nove aulas inovadoras na universidade. Campinas, SP: Papirus, 2011.

ZABALZA, M.A.; ZABALZA, M.A. El desafío de una educación innovadora. Multiversidad Management. out./nov., 2013.

ZABALZA, M. A. Ser profesor universitario hoy. La Questión Universitaria. N.5. 2009. (p.6981).

. Uma nova didáctica para o ensino universitário: respondendo ao desafio do espaço europeu de ensino superior. In: Sessão Solene comemorativa do Dia da Universidade - 95 aniversário da Universidade do Porto. Porto, Faculdade de Psicologia e Ciências da Educação, 2006.

- Innovación en la Enseñanza Universitaria. Contextos educativos: Revista de educación, № 6-7, 2003-2004. (p. 113-136). 